\title{
Notas sobre sujeito e autonomia na intervenção psicossocial
}

\author{
Notes about the subject and autonomy in psychosocial intervention \\ Notas acerca del sujeto y autonomía en la intervención psicosocial
}

\section{Maria Lucia Miranda Afonso*}

\begin{abstract}
Resumo
$\mathrm{O}$ artigo busca fazer uma revisão teórica que possa subsidiar o conceito de autonomia do sujeito na intervenção psicossocial. Nesse sentido, aborda a relação entre o sujeito, a linguagem e os discursos sociais. Enfatiza as possibilidades de produção do sentido apesar das sobredeterminações da ideologia e do inconsciente. Discute como o ato de interpretar está em uma relação dialética com a ação no contexto. Em seguida, aborda a autonomia como um processo ligado à práxis do sujeito, tomado como sujeito individual e coletivo. Retoma a dimensão política e social da autonomia que deve ser trabalhada na intervenção psicossocial. Reafirma a ideia matriz da intervenção psicossocial que postula a autonomia como trabalho de interpretação e processo de mudança do sujeito e da sociedade.
\end{abstract}

Palavras-chave: Intervenção psicossocial, sujeito social, autonomia, discurso, práxis.

\begin{abstract}
The paper reviews some theoretical approaches that aim to provide assistance for the conceptualization of autonomy of the subject within the psychosocial intervention processes. It addresses the relationship between subject, language and social discourses. It emphasizes the possibilities for the production of meaning in spite of the social determinations embroiled in ideology and unconscious. It discusses that interpretation is dialectically related to activity in the social context. It presents autonomy as a process linked to the praxis of individual and collective subjects. It resumes the social and political dimension of autonomy to be worked out in the process of psychosocial intervention. It reaffirms the main idea of psychosocial
\end{abstract}

Texto recebido em setembro de 2011 e aprovado para publicação em janeiro de 2012.

Coordenadora da Especialização em Intervenção Psicossocial no Contexto das Políticas Públicas (Centro Universitário UMA, Belo Horizonte-MG); professora do Mestrado Interdisciplinar em Gestão Social, Educação e Desenvolvimento Local (Centro Universitário UNA-BH); consultora para programas sociais; professora aposentada da UFMG. E-mail: luciaafonso@ibest.com.br. 
intervention: autonomy as work of interpretation and changing process of the subject and the society.

Keywords: Psychosocial intervention, social subject, autonomy, discourse, práxis.

\section{Resumen}

El artículo hace una revisión teórica que pueda subsidiar el concepto de autonomía de lo sujeto en la intervención psicosocial. Aborda la relación entre lenguaje, sujeto e discursos sociales. Enfatiza las posibilidades de producción del sentido a pesar de las sobre determinaciones de la ideología e del inconsciente. Discute como el acto de interpretar está en una relación dialéctica con la acción del sujeto en su contexto social. Aborda a autonomía como proceso ligado a la praxis del sujeto, tomado como sujeto individual y colectivo. Retoma la dimensión política y social de la autonomía a ser trabajada en la intervención psicosocial. Reafirma la idea de la intervención psicosocial que postula la autonomía como trabajo de interpretación y proceso de mudanza del sujeto y de la sociedad.

Palabras clave: Intervención psicosocial, sujeto social, autonomía, discurso, práxis.

ma frase de Karl Marx (1974, p. 59) pode ser identificada com a ideia matriz da intervenção psicossocial: "Os filósofos se limitaram a interpretar o mundo. Diferentemente, cabe transformá-lo”. Não por acaso, em sua proposta de pesquisa-ação, Kurt Lewin reescreve essa frase, afirmando: "Se você realmente deseja conhecer alguma coisa, tente transformá-la” (Lewin, 1951, citado por CDBS, 2008).

A proposta de associar conhecimento e intervenção, em um mesmo processo, exige o aprofundamento de questôes sobre o sujeito e os contextos da intervenção bem como sobre a ética dos processos de mudança. Nesse artigo, fazemos uma reflexão sobre o sujeito da intervenção psicossocial em sua relação com os discursos e a práxis social.

\section{A intervenção psicossocial e a ideia de autonomia}

A proposta de uma intervenção sobre a sociedade é tão antiga quanto o Estado. Mas a ideia de uma intervenção psicossocial desenvolvida junto com 
os sujeitos sociais surge no contexto das lutas por autonomia da sociedade diante do Estado. No século XX, a teoria da mudança social foi alvo de acirrado debate que colocava em questão a sobredeterminação histórica dos sujeitos e a sua capacidade de romper com formas instituídas, criando formas instituintes em processos participativos. Ou seja, estava em cheque a questão da autonomia.

Como prática da Psicologia social, que consideramos um campo interdisciplinar, a intervenção psicossocial também deve ser interdisciplinar. Orienta-se para processos de mudança, em contextos diversos, com base na demanda dos sujeitos envolvidos e na análise crítica das relações sociais no cotidiano dos grupos, instituições e comunidades.

Em texto clássico, Jean Maisonneuve (1977) argumenta que a intervenção psicossocial pode ser classificada como autoritária (ou tecnocrática), na qual especialistas julgam saber e determinam como deve ser a mudança social, à revelia dos sujeitos nela envolvidos; demiúrgica (ou, poderíamos dizer, populista), em que especialistas se limitam a tentar responder às encomendas explícitas feitas pelos sujeitos, sem preocupação com a sua elaboração; ou democrática (ou maiêutica), quando, em uma relação que busca diluir as hierarquias, existe o respeito pela demanda e uma proposta reflexiva visando à elaboração, com os sujeitos, da sua demanda, dos sentidos, projetos e estratégias de mudança.

André Lévy (2001) entende que as práticas de intervenção psicossocial de cunho democrático e participativo envolvem (1) produção de conhecimento do grupo-sujeito sobre si mesmo e sobre o seu contexto com a cooperação do sujeito-analista; e (2) produção de ação sobre o mundo, por meio de escolhas dos sujeitos individuais e coletivas sobre como agir no contexto histórico-social. Assim, a intervenção psicossocial produz reflexão ao mesmo tempo em que visa à ação.

Finalmente é preciso lembrar, conforme Machado (2004), que o principal objetivo da intervenção psicossocial não é um projeto predefinido de mudança pautado em uma racionalidade técnica e sim o desenvolvimento da autonomia dos sujeitos. Mesmo quando referenciado em conhecimentos técnicos, a mudança é um processo que deriva do desejo de autonomia e que deve oferecer condiçôes para o seu desenvolvimento. Não se trata de definir qual é a "mudança certa" para um dado grupo social e sim de construir com ele as possibilidades de transformação que ampliam e desenvolvem a sua autonomia.

Todavia, como nos lembra Barus-Michel (2008), buscar a autonomia significa lidar com a questão da sobredeterminação histórica, pois a autonomia 
está ligada à capacidade do sujeito de produzir sentidos e de fazer escolhas dentro do contexto social.

\section{A autonomia do sujeito na linguagem e nos discursos sociais}

Ao final do século XIX, as principais teorias da linguagem postulavam a existência de um indivíduo falante, que se utilizava da língua para expressar racionalmente seus pensamentos e emoções. Ao longo do século XX, com a incorporação da "questão" da ideologia e do inconsciente às teorias linguísticas, a ideia de indivíduo passou a ser criticada por sua pretensão de homogeneidade, racionalidade e autonomia. Falou-se, então, de um sujeito cindido e assujeitado à ideologia e ao inconsciente. Questionou-se o sujeito como autor de sua fala e de sua história. Entretanto, a crítica ainda deixava uma pergunta: se o sentido não é produzido pelo sujeito, como, por quem, por quais processos é ele produzido? Qual seria a possibilidade de autonomia dos sujeitos sociais contidos em suas sobredeterminações históricas?

\section{A relação dialética entre discurso exterior e discurso interior}

Em obra publicada pela primeira vez em 1929, Bakhtin (1981) critica as duas orientações tradicionais em linguística sobre a relação entre psiquismo e linguagem. $O$ subjetivismo idealista, que atribuía a função criadora da linguagem ao psiquismo individual, e o objetivismo abstrato, que considerava a língua como um sistema estável que impunha as suas leis objetivas à consciência subjetiva. Bakhtin oferece, então, uma concepção de língua e linguagem, em que subjetividade e objetividade se interligam em contínua dialética.

Para Bakhtin (1981), a língua é um sistema em evolução contínua e há uma relação entre a consciência subjetiva e o sistema de normas linguísticas. O sujeito serve-se da língua para efetuar suas enunciaçóes em um contexto, o que implica ressignificar a forma utilizada que, como signo variável e flexível, é adaptada ao contexto. O processo de ressignificação leva em conta o ponto de vista do emissor e do receptor, pois deve ser compreendido por ambos no contexto. Ambos se engajam na ressignificação, o que implica sempre um contexto ideológico preciso: "A palavra está sempre carregada de um conteúdo ou de um sentido ideológico ou vivencial" (Bakhtin, 1981, p. 95).

Tanto a enunciação quanto a compreensão de um enunciado tem caráter social e histórico. É por meio dessa relação dialética com a linguagem que a consciência individual se forma, sendo, ao mesmo tempo, construída por 
seu contexto e força ativa dessa construção. A consciência individual é um fato socioideológico que toma forma e existência nos signos criados por um grupo organizado no curso de suas relaçôes sociais (Bakhtin, 1981).

O processo de expressão-enunciação é sobredeterminado pelas condições reais da enunciação, e o diálogo pressupõe uma reflexão sobre a "recepção ativa do discurso de outrem". Assim, Bakhtin mostra a importância do discurso interior: "Aquele que apreende a enunciação de outrem não é um ser mudo, privado da palavra, mas ao contrário um ser cheio de palavras interiores" (Bakhtin, 1981, p. 147). A atividade mental é mediatizada pelo discurso apreendido do exterior e oscila entre a tomada de consciência e a elaboração ideológica:

Pode-se dizer que não é tanto a expressão que se adapta ao nosso mundo interior, mas o nosso mundo interior que se adapta às possibilidades de nossa expressão, aos seus caminhos e orientaçôes possíveis. Chamaremos a totalidade da atividade mental centrada sobre a vida cotidiana, assim como a expressão que a ela se liga, ideologia do cotidiano, para distingui-la dos sistemas ideológicos constituídos, tais como a arte, a moral, o direito, etc. A ideologia do cotidiano constitui o domínio da palavra interior e exterior desordenada e não fixada num sistema, que acompanha cada um de nossos atos ou gestos e cada um dos nossos estados de consciência. Considerando a natureza sociológica da estrutura da expressão e da atividade mental, podemos dizer que a ideologia do cotidiano corresponde, no essencial, àquilo que se designa, na literatura marxista, sob o nome de psicologia social (Bakhtin, 1981, p. 118-119) [grifo nosso].

A relação entre significado e realidade não é de mero espelhamento. Bakhtin (1981) argumenta que Psicologia e ideologia são questôes a serem tratadas de forma conjunta. "Nós afirmamos que uma só e mesma chave nos dá o acesso objetivo às duas esferas. Essa chave é a filosofia do signo, a filosofia da palavra, enquanto signo ideológico, por excelência” (Bakhtin, 1981, p. 57). Não seria possível traçar uma fronteira definida entre o psiquismo e a ideologia, pois todo signo exterior precisa, para sobreviver, de ser continuamente renovado pelos processos de compreensão, emoção e assimilação no contexto interior.

A contribuição de Bakhtin nos permite pensar a autonomia do sujeito com base na dialética entre pensamento e linguagem no contexto histórico. Porém, quando reinserimos essa questão no xadrez complexo dos discursos sociais e das relações de poder, somos obrigadas a reexaminá-la, de novo e... de novo! 


\section{Jogando xadrez com a morte: os discursos sociais e a polifonia do sujeito}

Reali \& Antiseri (1991) relatam que a diferença entre língua e fala, elaborada por Saussure, está na base da visão estruturalista sobre a relação entre sujeito e linguagem. Conforme esses autores, Saussure considerava a língua como um fato social exterior ao indivíduo, um sistema de sinais que este aprende a usar para pensar e se comunicar, sendo a fala um ato individual da vontade e inteligência (Reali \& Antiseri, 1991, p. 887). Esses estudiosos nos remetem à metáfora do jogo de xadrez, usada por Saussure para explicar essa ideia. No xadrez, pode-se variar o material de que são feitas as peças sem que isso altere as regras do jogo. Porém, quando o número de peças varia, altera-se a gramática (as regras) do jogo. Os sinais linguísticos seriam como as peças de xadrez e valeriam pela sua forma, não pela sua substância (Reali $\&$ Antiseri, 1991, p. 888).

A abordagem estruturalista saussuriana influenciou diversos autores no século XX, colocando em cheque a autonomia do sujeito nos sistemas linguísticos. Anos mais tarde, conforme Reali \& Antiseri (1991), a antropologia estrutural de Lévi-Strauss veio comparar a história humana com um jogo de xadrez, em que as regras do jogo determinam o deslocamento das peças. $\mathrm{Na}$ abordagem estruturalista, seria necessário captar as regras que "estruturam não apenas as configurações da vida social dos homens, mas também os seus produtos mentais" (Reali \& Antiseri, 1991, p. 947).

Conforme sintetiza Lobato (2008), na teoria antropológica de LéviStrauss, a vida social se baseia na troca, e esta se passa, fundamentalmente, nos sistemas simbólicos (regras matrimoniais, relaçôes econômicas, arte, ciência, etc.), dirigidos por estruturas mentais inconscientes. Assim, a origem das trocas, "muito além do pensamento consciente e das razōes explicitamente confessas, estaria no inconsciente do espírito humano" (Lobato, 2008, p. 32). Mas o que viria a ser esse sistema simbólico e que tipo de clausura ele impõe ao sujeito social? Como os conteúdos da cultura se colocariam muito além do pensamento consciente?

Lépine (1974) apresenta a concepção de Lévi-Strauss sobre o inconsciente, para quem este é "uma estrutura vazia":

Lévi-Strauss expulsa do inconsciente todos os conteúdos, que passam a ser recebidos pelo subconsciente. Este último seria um aspecto da memória. O inconsciente, para Lévi-Strauss, é uma atividade de natureza lógica, intelectual, que organiza os conteúdos inarticulados aos quais se aplica. Mas estes conteúdos 
não lhe pertencem. É também o conjunto de formas de operaçôes e de organização possíveis, nas quais esta atividade se manifesta, sempre as mesmas em todos os homens, em todos os tempos, universais, imutáveis (Lépine, 1974, p. 57-58).

É uma concepção da cultura semelhante à da língua dentro da linguística estruturalista, como uma atividade cujas regras os falantes sabem falar/seguir, mas das quais não são nunca completamente conscientes e, portanto, não sabem enunciar. $\mathrm{O}$ sujeito falante seria determinado tanto pelo inconsciente quanto pela ideologia (Brandão, 1985).

Lépine (1974) argumenta que, ao traduzir o inconsciente como uma "razão natural", que "se pensa no ser humano" e recebe todo o seu significado da ordem cultural, Lévi-Strauss o diferencia dos conteúdos da consciência. Assim, a ordem psicológica (ou os conteúdos conscientes) cria a ilusão do indivíduo como um ser autônomo do social. Mas é o inconsciente que faz a mediação entre o sujeito e a cultura, entre o eu e os outros (Lépine, 1974). Ainda assim, podemos encontrar em Lévi-Strauss (1971) elementos que indicam a possibilidade de que o sujeito apreende, em parte, essas relações:

Deste modo a compreensão das formas inconscientes da atividade do espírito (que só pode ser objetiva) nos conduz, apesar de tudo, à subjetivação, já que é a mesma operação que nos permite, em psicanálise, reconquistar nosso eu mais profundo e, na investigação etnológica, chegar também ao mais profundo dos outros, como a um outro nós (Lévi-Strauss, 1971, p. 28) [grifo nosso].

A teoria estruturalista foi criticada por minimizar a possibilidade de autonomia dos sujeitos e da produção de novos sentidos na história. De um lado, já não é possível manter a ilusão de um sujeito totalmente autônomo. De outro, a sua total submissão às estruturas sociais é questionável pela história humana, que contém, sempre, crise e transformação.

Por exemplo, apesar de concordar com o princípio de que a capacidade de elaborar símbolos e comunicar a experiência é um produto do espírito humano (e não resulta diretamente da organização da sociedade), Godelier (2001) afirma que é necessário compreender essa capacidade a partir da visão que uma sociedade usa, em uma época determinada, para inventar e exprimir a si própria. A visão de mundo de uma sociedade é histórica e, portanto, é preciso mais do que "estruturas inconscientes do espírito" para explicar as transformações das produçóes conscientes do ser humano (Godelier, 2001, p. 37).

O pensamento humano não se limita a pensar relações vividas. Também descobre e mesmo constrói relações entre essas relações. Essa capacidade 
de imaginar está presente na relação do ser humano com a natureza e com a sociedade. "O pensamento produz o real social combinando duas partes dele mesmo, dois poderes distintos que se completam sem se confundir: a capacidade de representar, de imaginar, e a de simbolizar, de comunicar as coisas reais ou imaginárias" (Godelier, 2001, p. 42).

Quanto ao inconsciente, há também, como veremos, argumentos favoráveis à capacidade do trabalho do sujeito humano e do espírito humano sobre essa instância de sua existência. É justamente por meio das "marcas" de outras falas na fala do sujeito que a psicanálise efetiva a sua aproximação de um inconsciente: duplos sentidos, atos falhos, ironias, entre outros. O sujeito se constitui em relação ao outro (sustentando uma "posição" na relação) e suas posições relativas se transformam não apenas em função de uma estrutura, mas, também, da sua história.

$\mathrm{O}$ inconsciente concebido como a linguagem do desejo é um elemento de subversão que provoca a cisão do eu. Entretanto o constante movimento entre consciente e inconsciente envolve processos diferenciados como os mecanismos de defesa, elaboração, rememoração, sublimação, entre outros, e é isso que torna uma análise possível (Brandão, 1985).

Para Leite (1994, p. 186), afirmar, no referencial psicanalítico, que o sujeito se constitui na linguagem não é o mesmo que dizer que ele é um "efeito" ou um "lugar vazio" onde a estrutura se expressa. A cisão entre consciente e inconsciente indica mais do que um "assujeitamento" do sujeito a uma ordem da qual ele "não sabe". Indica, também, a necessidade de mediaçôes efetuadas por uma economia psíquica, envolvendo tanto significados inconscientes quanto a capacidade de elaboração desses significados, na confluência entre o princípio do prazer e o princípio da realidade, dentro de um contexto social e histórico.

É como se, apreendidas as regras em um jogo de xadrez, o sujeito tentasse, por meios variados (que vão da obediência às regras, ao blefe, à trapaça e à tentativa de invenção de novas regras), ganhar a partida, isto é, inscrever o seu desejo na gramática do jogo, ou revolucionar a gramática do jogo para aí inscrever o seu desejo. Nesse sentido, o sujeito luta contra a sua morte (ou assujeitamento) e se vê "fadado" a produzir sentidos em uma busca incessante, ainda que mesclada com elementos de alienação, autoengano e assim por diante.

A concepção de assujeitamento do indivíduo aos discursos sociais e ao inconsciente motivou Michel Foucault (1970) a anunciar "a morte do sujeito”. Foucault se referia ao fim de uma concepção da autonomia baseada 
na racionalidade individual. Ao mesmo tempo, ele nos apresenta a um novo personagem: o sujeito político na ordem dos discursos.

Ao se passar de uma concepção ampla de "linguagem" para uma concepção de "discurso", passa-se a se considerar o sujeito dentro de um mundo simbólico cuja estrutura está submetida às dimensóes da política, da economia, entre outras. Maingueneau (1993) entende o discurso como o uso da linguagem para a produção do sentido entre os interlocutores. Porém, como esse conceito é muito amplo, introduz a noção de formações discursivas, que são conjuntos de enunciações que os sujeitos produzem, com base em suas posiçôes e relaçōes dentro de um contexto social e histórico. Nessa perspectiva, as cisões do sujeito adquirem caráter político: há cisão não apenas entre o que se quer dizer e o que se diz, mas, também, entre discurso e prática, entre intenção e resultados da ação na história. E as cisões têm origem tanto no "espírito humano" quanto na história.

\section{O sujeito político na desordem dos discursos}

A contribuição de Michel Foucault é vasta e diversificada. Neste artigo, vamos recortar algumas de suas consideraçóes sobre o discurso e o poder, que têm implicações para a compreensão dos sujeitos e sua ação na sociedade. Em sua obra "História da sexualidade: a vontade de saber", Foucault (1980) nos adverte contra uma postura reducionista na análise do discurso. Nenhuma fórmula predeterminada pode ser inteiramente capaz de captar o movimento histórico que é composto por diversas estratégias discursivas, que mudam com estratégias de poder vigentes:

Não se deve fazer a divisão binária entre o que se diz e o que não se diz; é preciso tentar determinar as diferentes maneiras de não dizer, como são distribuídos os que podem e os que não podem falar, que tipo de discurso é autorizado ou que forma de discrição é exigida a uns e outros. Não existe um só, mas muitos silêncios e são parte integrante das estratégias que apoiam e atravessam os discursos (Foucault, 1980, p. 30).

Foucault nos aponta para uma ordem do discurso, social e politicamente organizada. Todavia sugere que há nela um movimento, uma "des-ordem" que se insurge e atravessa os diferentes discursos. Inclusive porque os discursos não são apenas instrumentos do poder. Eles são também os objetos disputados pelas relações de poder: poder de enunciar, o que, em política, pode equivaler ao poder! Nesse sentido, temos uma dialética do discurso dentro de um processo histórico que contém tanto ordem quanto desordem e que não 
se esgota em uma análise dos sentidos já dados pelas estruturas sociais. As relaçôes de poder existentes são determinantes, porém são também sujeitas às mudanças societárias.

Uma das grandes contribuições de Foucault foi justamente a concepção de poder que se refere a uma "situação estratégica" e não a uma "estrutura determinada", abrindo espaço para se perceber o sujeito em ação no interior das correlações múltiplas de forças na sociedade, a um só tempo recebendo e resistindo a esse impacto.

Para Foucault (1980, p. 88-97), o poder está em toda parte, não porque englobe tudo, mas porque provém de todos os lugares. "O poder não é uma instituição e nem uma estrutura, não é uma potência de que alguns sejam dotados: é o nome dado a uma situação estratégica complexa em uma sociedade determinada [grifo nosso]" (p. 89). O poder se exerce a partir de inúmeros pontos e em meio a relações desiguais e móveis. As relações de poder são imanentes aos outros tipos de relaçôes. As correlações de força múltiplas nos grupos e instituições servem de suporte a amplos efeitos de clivagem que atravessam o conjunto do corpo social. As relações de poder são, ao mesmo tempo, intencionais e não subjetivas: não há poder que se exerça sem uma série de miras e objetivos. A racionalidade do poder não é efeito da vontade individual. E a resistência, em suas diversas manifestações, é sempre um contraponto que compõe as relações de poder.

Foucault (1980) afirma que a lei é constitutiva tanto do desejo quanto da falha que o instaura. Portanto seria ilusão buscar um desejo exterior ao poder. Entretanto o poder tem também uma vertente positiva, no sentido de que cria formas de existência, organiza, nomeia e dá validade a essas formas. Assim, não se deve "imaginar um mundo do discurso dividido entre o discurso admitido e o discurso excluído, ou entre o discurso dominante e o dominado; mas, ao contrário, como uma multiplicidade de elementos discursivos que podem entrar em estratégias diferentes" (Foucault, 1980, p. 96).

Uma vez que o "lugar" ocupado pelo sujeito em suas relações sociais não totaliza a sua subjetividade e que ambos são importantes na construção do significado, Foucault (1970) sugere que se busque definir as relações possíveis entre: (a) quem enuncia (pessoas/grupos/instituições), (b) a partir de que lugares enuncia e (c) que discursos são enunciados. Por isso mesmo, a análise dos discursos enfoca dois níveis: "o de sua produtividade tática (que efeitos recíprocos de poder e saber proporcionam) e o de sua 
interação estratégica (que conjuntura e que correlação de forças torna necessária sua utilização em tal ou qual episódio dos diversos confrontos produzidos)" (Foucault, 1980, p. 97) [grifo nosso].

Falar em produtividade tática e interação estratégica é justamente reconhecer a ação histórica dos sujeitos envolvidos em relações sociais, que são sempre relações de poder e saber. Pensamos a autonomia a partir da ação do sujeito, da sua negatividade diante do instituído, da sua resistência e da sua possibilidade de produção de novos sentidos e práticas. O sujeito foulcaultiano nos parece vivo porque é político e está fadado, nas estratégias em jogo, a produzir sentidos e a se posicionar no mundo social. A anunciada morte do sujeito acabou por se converter no pregão de seu renascimento.

\section{De suas próprias cinzas...: a hermenêutica crítica}

Em "Interpretação e Ideologia”, Paul Ricoeur (1983) discute a capacidade do sujeito de interpretar de forma crítica e transformar as sobredeterminaçôes da ideologia e do inconsciente. Para tal, utiliza-se do recurso de contrapor dois autores (H. G. Gadamer e J. Habermas), apresentando, ao final, a sua elaboração própria. Uma vez que é a posição de Ricoeur que nos referencia, neste debate, vamos resumir as proposiçôes de Gadamer e de Habermas com base no texto de Ricoeur (1983) e, quando necessário, complementar com os esclarecimentos oferecidos em Reali \& Antiseri (1991).

Conforme resumem Reali \& Antiseri (1991, p. 629-632), Gadamer concebe o ato interpretativo como ato de uma mente tabula plena, isto é, que se aproxima do texto (tomado aqui com o sentido de "mundo"), com sua pré-compreensão, expectativas e pré-suposições. É partindo de sua memória cultural (linguagem, mitos, etc.) que o intérprete tece a sua interpretação do texto/mundo. Cada interpretação se efetua à luz do que se supõe conhecer, o que muda permanentemente. A tarefa de interpretação, embora possível, está sempre inacabada, uma vez que é infinita. $\mathrm{O}$ ato de interpretar vai além das intenções originais do intérprete. As hipóteses interpretativas vão se sucedendo e fazem emergir progressivamente a alteridade (como as outras visões possíveis) do texto/mundo. Nesse movimento, é possível para o intérprete tomar consciência das próprias pressuposiçôes e pré-juízos.

Para Gadamer, conforme nos explicam Reali \& Antiseri (1991, pp. 634635), o conhecimento se desenvolve na superação de todos os preconceitos, mas pode ele mesmo ser um preconceito. A tradição se torna importante porque em toda mudança histórica haveria um correlato de conservação. Porém também pode ser fonte de enganos. $\mathrm{O}$ ato de compreender faz parte da 
experiência dialética: a consciência (que faz a experiência de compreender) se subverte, volta a si, pois adquiriu um novo horizonte dentro do qual se insere o seu objeto de compreensão. Porém uma crítica exaustiva dos preconceitos (e das ideologias) seria impossível, pois o "ponto zero", de onde ela poderia ser feita, não existe. Trata-se, então, da consciência de estar exposto à história e à sua ação.

Voltando à leitura de Ricoeur (1983), temos, em Gadamer, um movimento que parte da eficácia da história sobre a consciência, mas engloba a consciência da eficácia da história e, finalmente, a consciência da história da eficácia, o que possibilita a emergência de uma visão crítica. Entretanto, argumenta Ricoeur, a contribuição de Gadamer, com a sua ênfase na tradição, deixa de lado a análise dos interesses sociais envolvidos na perpetuação das visões hegemônicas de mundo. Ricoeur passa, então, à discussão da crítica das ideologias.

Ricoeur (1983) observa que, para Habermas, o conhecimento é um empreendimento que se dá justamente porque existe o "interesse" sendo que a tarefa da filosofia crítica é desmascará-los. A ideologia é um conhecimento pretensamente desinteressado que dissimula um interesse sob a forma de racionalização. A reflexão é regulada pelo interesse de emancipação, também chamado de autonomia, de autorreflexão, de independência.

Assim, conforme lemos em Ricoeur (1983), Habermas considera que a distorção da compreensão está ligada à ação repressiva de uma autoridade (ou seja, à violência material ou simbólica). Isso póe em relevância os conceitos de censura (um conceito de origem política que passa pela psicanálise e é incorporado às ciências sociais críticas), de trabalho e de poder (que não são enfatizados pela hermenêutica clássica). A dominação se produz na esfera da ação comunicativa, por meio de distorções da linguagem e da comunicação. $\mathrm{O}$ esforço de compreender não se restringe à dimensão da linguagem, porque a própria linguagem existe dentro de uma relação trabalho-poder-linguagem.

Assim, para que ocorra uma dissolução das ideologias, são necessários procedimentos explicativos (a partir do distanciamento relativo entre sujeito e objeto) e não puramente compreensivos (em que há um pertencimento relativo entre sujeito e objeto), implicando conflitos e escolhas políticas sobre os sentidos a serem construídos e as ações a serem empreendidas. Ademais, a crítica das ideologias exige uma situação de comunicação sem coação. Ideia esta que não pode ser confundida com uma "situação de fato", mas que se coloca como ideia reguladora, utopia, projeto do fim de toda violência (Ricoeur, 1983). 
Ricoeur (1983) argumenta que (a) a hermenêutica (com Gadamer) reconhece a importância das condições históricas a que está submetida toda compreensão humana, e (b) a crítica das ideologias (com Habermas) dirige-se contra as distorções da comunicação humana, dentro das relações existentes de dominação. Ricoeur entende que essas duas formulações são legítimas e se interpelam mutuamente. Nesse sentido, Ricoeur (1983) propõe uma hermenêutica crítica (ou hermenêutico-dialética) que supere a dicotomia entre "explicar" e "compreender". Nela, o discurso não depende apenas de uma instância simbólica e interpretativa, mas envolve práxis social. A condição para a compreensão é, justamente, a reconstrução da obra/mundo, em um processo dialético. $\mathrm{O}$ sujeito que interpreta precisa, em primeiro lugar, deixarse atravessar e transformar-se pela obra/mundo. Envolve-se em um trabalho de apropriação da linguagem e do mundo, que implica em transformá-los (Ricoeur, 1983; Ricoeur \& Thompson, 1981). O intérprete é visto como um "brincante", alguém que brinca com os sentidos, recriando-os em um "como se", para que a interpretação se torne possível. Em vez de procurar um sentido "oculto atrás do texto", a hermenêutica crítica busca um mundo diante dele. Ou seja, o saber do sujeito sobre si mesmo deixa-se instruir pelo mundo (Ricoeur \& Thompson, 1981).

Assim, a compreensão (do texto/mundo) não é algo de que a subjetividade do leitor teria a chave, uma vez que essa subjetividade é tão irrealizada quanto o próprio mundo. A compreensão incide também, de maneira crítica, nas ilusões às quais o sujeito está submetido. Daí é que se torna possível a crítica aos conteúdos da consciência e às relações de poder que produzem a consciência (Ricoeur \& Thompson, 1981).

É necessário enfatizar que a hermenêutica dialética, ao incorporar a crítica das ideologias, passa a conjugar a sequência trabalho-poder-linguagem. Ou seja, não reduz a produção do sentido à interpretação, mas interliga a possibilidade de interpretar ao agir no mundo social.

\section{Dos discursos à práxis social: o trabalho de ser sujeito}

Com base na discussão acima, retomamos a ideia de que a autonomia é um processo que inclui, ao mesmo tempo, trabalho de interpretação e de transformação do mundo. Vamos discutir como essa ideia se estende à concepção de sujeito individual e coletivo.

Alain Touraine (1998) critica a sociedade moderna como uma sociedade sem sujeitos, no sentido de que as decisões tomadas por estes são ditadas pela racionalidade dominante, sem envolver a sua capacidade reflexiva. Critica a 
modernidade pautada apenas na eficácia da racionalidade instrumental, a técnica e a ciência, de forma que acaba por esconder a emergência do sujeito humano como liberdade e como criação.

$\mathrm{Na}$ modernidade, a racionalização da sociedade está em contínua tensão com a capacidade do indivíduo de conceber a si mesmo com um ator histórico e social, sendo capaz de tornar-se sujeito de sua história. Esses três termos se definem pelas suas inter-relaçôes, sendo que "o sujeito" é o esforço que faz o "ator social" para se tornar autor de sua própria história. Entretanto, para que o sujeito apareça, é necessário que o indivíduo reconheça em si a presença de um si mesmo junto com a vontade de ser sujeito e a busca por autonomia. A mudança social não pode ser meramente resultado de um planejamento racional por parte do Estado ou das pressões do mercado. É necessária a participação dos sujeitos sociais (Touraine, 2009a, p. 213-245).

O abandono de um paradigma determinista (a ideia de que a estrutura determina o sujeito) exige cada vez mais que se pense na relação entre os indivíduos (os seres humanos individuais), o ator social (o agente de mudanças) e o sujeito (a instância de autonomia, um si mesmo capaz de reflexividade e escolhas). Assim, quando se fala no sujeito, é impossível separá-lo da sua situação social. Ao mesmo tempo, o indivíduo não poderia, isoladamente, defender a sua autonomia dentro do contexto social (Touraine, 2009a).

Para tal, é preciso o engajamento mútuo no processo de mudança, sendo que a ideia de sujeito não é separada da ideia de movimento social. Portanto, Touraine (2009b) recoloca as classes sociais e os movimentos sociais como "sujeitos" da história. O movimento histórico precisa mais do que de situações dialógicas ou de comunicação ideal. Exige a crítica e a denúncia dos poderes, bem como a força da ação coletiva, que pode proteger os direitos dos indivíduos e permitir que o sujeito sobreviva. $\mathrm{O}$ processo de subjetivação é psicológico e político. O "sujeito" não se limita a ser uma "reflexão" ou um "diálogo" do indivíduo sobre si mesmo. "É uma ação, um trabalho."

Nessa perspectiva, Castoriadis introduz a sua concepção de sujeito e subjetividade. Para ele, "a questão do sujeito não é a questão de uma substância, mas de um projeto" a ser realizado em parte pelos indivíduos e, ainda, "em função de uma transformação que se refere não apenas aos seres humanos na sua singularidade, mas à sociedade em seu conjunto" (Castoriadis, 1999, p. 35, 45-46). A subjetividade é definida como "a 
capacidade de receber o sentido, de fazer algo com ele e de produzir, dar sentido, fazer com que cada vez seja um sentido novo" (Castoriadis, 1999, p. 35).

Para Castoriadis (1999, p. 35), a instância subjetiva pode ser vista em seis diferentes níveis: (a) o ser vivo, ou seja, o ser-para-si; (b) o psíquico, na pluralidade das suas instâncias; (c) o indivíduo socialmente produzido, fruto da transformação do psíquico pela sociedade por meio da linguagem; (d) o sujeito humano propriamente dito, ou a subjetividade humana, definida por dois aspectos que produzem a diferença específica com o que precede: a reflexividade e a capacidade de atividade deliberada; (e) a própria sociedade, com sua "si-dade", sua maneira de ser e de interpretar o mundo; (f) a sociedade quando tem mecanismos que lhe conferem reflexividade e capacidade de atividade deliberada [grifo nosso].

A subjetividade, assim, é um atributo não apenas do indivíduo, ${ }^{1}$ mas também dos grupos e das coletividades, e envolve a interação, a comunicação, a intersubjetividade dentro de um contexto social e histórico. Mas não se resume a isso. É necessário haver um movimento instituinte que revela e constrói a própria subjetividade como tensão, projeto e capacidade de ação deliberada. A subjetividade envolve um trabalho de ser sujeito inserido na práxis social, indo do sujeito individual ao coletivo (Castoriadis, 1982; 1999).

Coloca-se então a questão da autonomia do sujeito, ou seja, da tensão entre as sobredeterminações históricas e a sua ação instituinte. O sujeito existe na relação com o outro. A autonomia é um trabalho intersubjetivo, coletivo e social que resulta da possibilidade de construção de instituiçôes que favoreçam a autonomia da própria sociedade. Assim:

A autonomia não é, pois, elucidação sem resíduo e eliminação total do discurso do Outro não reconhecido como tal. Ela é instauração de uma outra relação entre o discurso do Outro e o discurso do sujeito. A total eliminação do discurso do Outro não reconhecido como tal é um estado não-histórico. [...] Existe a possibilidade permanente e permanentemente atualizável de olhar, objetivar, colocar à distância e finalmente transformar o discurso do Outro em discurso do sujeito (Castoriadis, 1982, p. 126-127).

\footnotetext{
Fazemos questão de lembrar que a importância dada ao indivíduo não é apenas uma questão de teoria, mas está historicamente vinculada à emergência dos direitos sociais e à ampliação dos direitos humanos, organizados em torno da discussão histórica sobre a dignidade humana, tanto do indivíduo quanto dos grupos e coletividades. Porém não teremos oportunidade de desenvolver melhor esse ponto neste artigo.
} 
O problema da autonomia está relacionado ao fato de que o sujeito encontra em si próprio um sentido que não é o seu e que tem que transformar por meio de sua atividade. A autonomia é essa relação na qual os outros estão sempre presentes como alteridade e como ipseidade do sujeito, sendo, mais do que uma relação intersubjetiva, uma relação social, propriamente dita. Essa relação não está limitada à dimensão psicológica. É também dimensão sócio-histórica: "É a união e a tensão da sociedade instituinte e da sociedade instituída, da história feita e da história se fazendo" (Castoriadis, 1982, p. 131).

Castoriadis (1982) coloca, em relações complexas, o sujeito, o outro e o social, concebendo a autonomia não como um "estado" de consciência, mas como processo, trabalho de ser com o outro em sociedade. Abarca a subjetividade, inclusive o inconsciente e os discursos sociais, sem se reduzir a eles. Pensa no sujeito como indivíduos, grupos, sociedades. Sociedade e psique são inseparáveis embora irredutíveis uma à outra. $\mathrm{O}$ fato de o sujeito existir em sociedade, e por meio da linguagem, não é o que determina o seu assujeitamento. Pelo contrário, pode fundar também o seu movimento de emancipação. É na instituição e na linguagem que o sujeito encontra uma abertura para o mundo. Ao mesmo tempo em que contribui para estruturar o sujeito, a linguagem lhe oferece possibilidades de criação e liberdade.

E o que permite, em uma sociedade, a construção de novos sentidos e significados? Para o autor, é a instância do imaginário que se articula com o real e o simbólico:

[...] Falamos de imaginário quando queremos falar de qualquer coisa inventada - quer se trate de uma invenção absoluta (uma história imaginada com todos os detalhes) ou de um deslizamento, de um deslocamento de sentido ou de símbolos que, já disponíveis, são investidos de outras significações que não são as normais ou canônicas [...] (Castoriadis, 1982, p. 154).

O simbólico expressa o real percebido, uma vez que é no contexto social que o percebemos. Porém, sem a instância imaginária, os sistemas simbólicos seriam uma repetição infindável dos mesmos significados. $\mathrm{O}$ simbólico só pode se referir ao real de forma fragmentada. A busca de integração e totalidade é um esforço do imaginário de preencher as faltas percebidas. O imaginário pode então produzir a "diferença" com o sentido instituído, fazer emergir o que era negado, reprimido ou simplesmente possibilitado (Castoriadis, 1982). 
Por sua vez, o imaginário é movido pelo desejo do sujeito (individual, coletivo) e não pode existir senão através de sua relação com o simbólico:

O imaginário deve utilizar o simbólico não apenas para se "exprimir", o que lhe é próprio, mas para "existir", para passar do virtual a alguma coisa além. O delírio mais elaborado assim como o fantasma mais secreto e vago são feitos de imagens, mas estas imagens existem como representantes de outra coisa, tendo portanto uma função simbólica. Mas, também, inversamente, o simbolismo pressupõe a capacidade imaginária. Porque pressupóe a capacidade de ver numa coisa aquilo que ela não é, de vê-la como outra que ela não é (Castoriadis, 1982, p. 154) [grifos do autor].

Reconhecer o entrelaçamento da função imaginária com o real-social e o simbólico é reconhecer a implicação do ser humano em sua história. Negar a importância do imaginário retira da sociedade qualquer possibilidade de liberdade, criação ou autonomia. Não podemos sair da história e da sociedade, mas podemos buscar os questionamentos e as ações possíveis para ressignificar e transformar a partir da própria sociedade e da história (Castoriadis, 1982).

A autotransformação da sociedade é um fazer político, no sentido profundo do termo, e ao qual Castoriadis dá o nome de práxis: "Chamaremos de práxis a este fazer no qual o outro ou os outros são visados como seres autônomos e considerados como o agente essencial do desenvolvimento de sua própria autonomia" (Castoriadis, 1982, p. 94).

A práxis não se confunde com um esquema de fins e meios ou planejamento técnico. Tem a autonomia como princípio e visa ao desenvolvimento e ao exercício dessa autonomia. É atividade consciente, mas é diferente da mera aplicação instrumentalizada de um saber. Isso porque todos os saberes que orientam a prática são sempre incompletos, provisórios e fragmentados, uma vez que não pode haver um saber absoluto sobre a história. Assim, compreensão e interpretação emergem constantemente da própria atividade. O sujeito não está separado da sua práxis e emerge dela como projeto de si mesmo. Nesse sentido, a instância última desse projeto não é (apenas) elucidação e sim transformação (Castoriadis, 1982).

Reencontramos aqui a exortação de Marx de que devemos ir além da interpretação e assumir a tarefa da transformação do mundo e, ainda, o dito lewiniano de que, de qualquer forma, para compreender o mundo, será necessário transformá-lo. Passemos, então, às nossas considerações finais. 


\section{Considerações finais}

Como define Lévy (2001), a intervenção psicossocial assume o interesse pela mudança social e pelas escolhas dos sujeitos, como processos grupais e coletivos, com efeitos de e sobre a linguagem, sendo que o próprio discurso é um lugar de mudança. Essa mudança é do social e dos sujeitos e precisa estar associada aos seus processos de autonomia.

As decisões que se tomam no processo de intervenção psicossocial criam contextos de mudança que, por sua vez, afetam os sujeitos envolvidos. São atos de palavra. Envolvem escolhas que, ainda que estejam referenciadas em um discurso técnico, são sempre políticas. É necessário ir além das interpretações discursivas e articular o trabalho da interpretação a um processo de mudança, sabendo, inclusive, que esta sempre envolverá riscos (Lévy, 2001).

Uma das questôes que se colocam hoje na prática dos psicólogos sociais é justamente como considerar tudo isso em uma sociedade desigual e complexa, em que a relação entre a sociedade civil e o Estado tem passado por profundas mudanças.

Vimos que, na intervenção psicossocial, há uma triangulação teórica entre sujeito, discurso e práxis social. Acreditamos que, nos processos de intervenção, torna-se importante conseguir analisar essa triangulação. Isso equivaleria a indagar, no campo político e social, quem são os sujeitos dos processos de intervenção psicossocial, seus interesses, suas relações, seus conflitos, seus projetos, suas possibilidades e seus recursos.

Sabemos que, hoje, um dos maiores campos de atuação para o psicólogo social é o das políticas públicas. Sabemos também que a intervenção nas políticas públicas nem sempre são orientadas pelos mesmos pressupostos e objetivos colocados pelo paradigma da intervenção psicossocial, havendo frequentemente uma tensão entre eles (Machado, 2004). Por exemplo, pode haver diferenças relevantes acerca do tipo de participação dos sujeitos e as formas de decisão no processo e, muitas vezes, a política pública objetiva resultados predefinidos mensuráveis enquanto a intervenção psicossocial visa à autonomia (Machado, 2004).

Entretanto, é preciso indagar se a intervenção psicossocial não teria uma contribuição para o campo das políticas públicas e se estas não poderiam (pelo menos enquanto se colocarem como políticas de defesa de direitos) provocar o desenvolvimento da intervenção psicossocial. Nesse sentido, é preciso superar o que arriscamos chamar de certo "basismo", ou a delimitação de trabalhos em pequenos grupos e comunidades locais, 
buscando responder às demandas imediatas dos sujeitos individuais, dentro de certa homogeneidade de interesses, sem uma contextualização ampla.

Consideramos desejável que a Psicologia social e a intervenção psicossocial desenvolvam análises (e trabalhos práticos) mais amplas sobre a mudança social, suas relaçôes com as políticas públicas, as diferentes possibilidades de atuação no âmbito das democracias participativas, buscando dar maior consistência para a triangulação estabelecida entre sujeitos, discursos e práxis social.

\section{Referências}

Bakhtin, M. (1981). Marxismo e filosofia da linguagem. (2. ed.). São Paulo: Hucitec. (Trabalho original publicado em 1929)

Barus-Michel, J. (2008). O sujeito e o destino. Psicologia em Revista, 14 (1), 17-36.

Brandão, H. N. (1985). Introdução à análise do discurso. (4. ed.). Campinas: Ed. da Universidade Estadual de Campinas.

Castoriadis, C. (1982). A instituição imaginária da sociedade. Rio de Janeiro: Paz e Terra.

Castoriadis, C. (1999). Para si e subjetividade. In: A. Pena-Vega \& E. P. Almeida. O pensar complexo: Edgar Morin e a crise da modernidade. (pp. 3546). Rio de Janeiro: Garamond.

CDBS (Complete Dictionary of Scientific Biography). (2008). Encyclopedia. com. Recuperado em 2 de outubro de 2011, de http://www.encyclopedia. com/doc/1G2-2830905863.html.

Foucault, M. (1980). História da sexualidade: a vontade de saber. (v. 1). Rio de Janeiro: Graal.

Foucault, M. (1970). L'ordre du discours. Paris: Gallimard.

Godelier, M. (2001). O enigma do dom. Rio de Janeiro: Civilização Brasileira.

Leite, N. (1994). Psicanálise e análise do discurso: o acontecimento na estrutura. Rio de Janeiro: Campo Matêmico. 
Lépine, C. (1974). O inconsciente na antropologia de Lévi-Strauss. São Paulo: Ática.

Lévi-Strauss, C. (1971). Introducción a la obra de Marcel Mauss. In: M. Mauss. Sociología y Antropología. Madrid: Technos.

Lévy, A. (2001). A mudança: esse obscuro objeto de desejo. In: M. N. da M. Machado et al. (org.). Psicossociologia: análise social e intervenção. (pp. 121131). Belo Horizonte: Autêntica.

Lobato, J. P. (2008). A dádiva como fator de integração social. Psicologia Plural, 28, 13-23.

Machado, M. N. da M. (2004). Práticas psicossociais. Pesquisando e intervindo. Belo Horizonte: Edições do Campo Social.

Maingueneau, D. (1993). Novas Tendências em Análise do Discurso. (2. ed.). São Paulo, Campinas: Pontes; Ed. da Universidade Estadual de Campinas.

Maisonneuve, J. (1977). Introdução à psicossociologia. São Paulo: Nacional; Edusp.

Marx, K. (1974). Teses contra Feuerbach. In: K. Marx. Manuscritos econômicofilosóficos e outros textos escolhidos. (José Arthur Giannotti, trad.). São Paulo: Abril Cultural.

Reali, G. \& Antiseri, D. (1991). História da Filosofia: do romantismo até os nossos dias. (v. 3.). São Paulo: Paulus.

Ricoeur, P. (1983). Interpretação e ideologias. Rio de Janeiro: Francisco Alves.

Ricoeur, P. \& Thompson, J. B. (1981). Hermeneutics and the human sciences: essays on language, action and interpretation. Cambridge: Cambridge University Press; Paris: Maison des Sciences de l'Homme.

Touraine, A. (2009a). O sujeito. In: A. Touraine. Crítica à modernidade. (pp. 213-245). Petrópolis: Vozes.

Touraine, A. (2009b). O sujeito como movimento social. In: A. Touraine. Crítica à modernidade. (pp. 248-268). Petrópolis: Vozes.

Touraine, A. (1998). O sujeito. In: A. Touraine. Poderemos viver juntos? Iguais e Diferentes. (pp. 68-111). Petrópolis: Vozes. 